\title{
WAVE PROPAGATION ON A FLUME: PHYSICAL MODELLING
}

\author{
J. M. P. Conde ${ }^{a, b, c}$, \\ R. Reis ${ }^{b}$, \\ C. J. Fortes ${ }^{\mathrm{b}}$, \\ and D. R. C. B. Neves \\ ${ }^{a}$ Universidade Nova de Lisboa \\ Faculty of Science and Technology \\ Dep. Mechanical and Industrial Engineering \\ Campus de Caparica \\ 2829-516 Monte de Caparica, Portugal \\ jpc@fct.unl.pt \\ ${ }^{\mathrm{b}}$ National Laboratory for Civil Engineering \\ Harbours and Maritime Structures Division \\ Av. do Brasil, 101 \\ 1700-066 Lisbon, Portugal \\ ${ }^{\mathrm{c}}$ Institute of Mechanical Engineering \\ (IDMEC/IST) \\ Av. Rovisco Pais, 1 \\ 1049-001 Lisbon, Portugal
}

ABSTRACT

The knowledge of wave transformation and breaking characteristics near coastline is essential for the nearshore hydrodynamics and the design of coastal structures. This paper describes a wide range of wave flume tests performed at the National Laboratory for Civil Engineering (LNEC), located in Lisbon (Portugal), which main objective was to study wave shoaling and breaking over a set of different gentle slopes for several incident waves and thus to contribute for a better understand of the hydrodynamics of wave transformation.

The experimental conditions, the measurement equipment, the incident wave characteristics, the type of measurements performed (free surface elevation and particle velocity) and the data obtained are described. Time and spectral analysis based upon the measured data are also performed and presented. For a regular wave with a period of $1.5 \mathrm{~s}$ and a height of $0.1 \mathrm{~m}$ are presented and discussed the following results: free surface elevation at selected sections along the flume; the spectral analysis; the significant wave height and average period along the flume; the particle velocity components at different locations along the flume; the average, maximum and minimum values of the longitudinal component of the velocity along the flume; the two dimensional distribution of the three components of the velocity; and longitudinal velocity component vertical profiles.

Keywords: physical modelling, wave flume, wave propagation, time analysis, spectral analysis

\section{NOMENCLATURE}

a wave amplitude, $\mathrm{m}$

E velocity component amplitude, $\mathrm{m} / \mathrm{s}$

f wave frequency, $\mathrm{Hz}$

d water depth, $m$

$\mathrm{H}$ wave height, $\mathrm{m}$

$\mathrm{T}$ wave period, $\mathrm{s}$

$\mathrm{V}$ velocity, $\mathrm{m} / \mathrm{s}$

$\mathrm{x} \quad$ longitudinal coordinate, $\mathrm{m}$

$\mathrm{y}$ transversal coordinate, $\mathrm{m}$

$\mathrm{z} \quad$ vertical coordinate, $\mathrm{m}$

\section{Greek symbols}

$\eta \quad$ free surface elevation referred to the mean water level, $\mathrm{m}$

\section{Subscripts}

$\begin{array}{ll}\text { av } & \text { average } \\ \mathrm{s} & \text { significant } \\ \max & \text { maximum } \\ \text { min } & \text { minimum } \\ \text { ref } & \text { reference } \\ \mathrm{X} & \text { longitudinal component } \\ \mathrm{y} & \text { transversal component } \\ \mathrm{Z} & \text { vertical component }\end{array}$

\section{INTRODUCTION}

The knowledge of the wave transformation and the wave breaking characteristics near the coastline is essential for the nearshore hydrodynamics and the design of coastal structures. Physical models and laboratory experiments are an important parcel of the research methodology for acquiring a better knowledge and characterization of these phenomena. The validation of the numerical models depends greatly on accurate and reliable experimental data.

Following this reasoning, a wide range of wave flume tests was performed at the National Laboratory for Civil Engineering (LNEC) to study the wave transformation and breaking considering different incident conditions.

Okamoto et al. (2010), Endres et al. (2011) and Neves et al. (2011, 2012) performed a set of experimental tests for incident regular wave conditions originating wave breaking, considering different bottom slopes. The work presented in this paper follows the methodology of these previous works, considering incident regular waves without wave breaking.

This paper presents the experimental layout, the incident wave conditions and the experimental procedures. Data and results from time and spectral analysis are presented for an incident regular wave with a period, $\mathrm{T}$, equal to $1.5 \mathrm{~s}$ and wave height, $\mathrm{H}$, 
equal to $0.1 \mathrm{~m}$. These results include: free surface elevation at five sections along the flume and the corresponding amplitude spectra; significant wave height, $\mathrm{H}_{\mathrm{s}}$, and average period, $\mathrm{T}_{\mathrm{av}}$, along the flume; velocity components, $\mathrm{V}_{\mathrm{x}}, \mathrm{V}_{\mathrm{y}}$ and $\mathrm{V}_{\mathrm{z}}$, at one section of the flume, measured at the middle of the water column; maximum, minimum and average values of the velocity longitudinal component along the flume; two-dimensional distributions of the velocity components, in the middle of the water column, in the $x y, x z$, and yz planes; average values of positive and negative velocity components amplitudes, $\mathrm{E}_{\mathrm{x}}, \mathrm{E}_{\mathrm{y}}$ and $\mathrm{E}_{\mathrm{z}}$, ratios along the flume; and longitudinal velocity component vertical profiles.

\section{EXPERIMENTS}

The experimental tests were performed in the wave flume represented in Fig. 1 and 2. This old regular wave flume was designed with a reduction of width to improve its hydraulic behaviour, by preventing unwanted transversal waves, and, at the same time, to enable an increase of the regular wave heights (due to shoaling at the $1 / 11$ bottom slope) produced by the limited capabilities of the original wave paddle. Nowadays, the flume is equipped with a piston-type irregular wave-maker system controlled by an $\mathrm{A} / \mathrm{D}$ converter and a personal computer. This wave maker can produce regular or irregular waves. A $10 \mathrm{~m}$ long $1 / 22$ slope beach profile, followed by a $10 \mathrm{~m}$ horizontal zone were constructed. This bottom was made out of concrete so there is no permeability. At the end of the flume there is a $1 / 20$ slope concrete bottom followed by a $1 / 2$ slope gravel beach. Porous blankets (horsehair sheets) were installed over the $1 / 20$ slope to reduce the reflected wave energy.

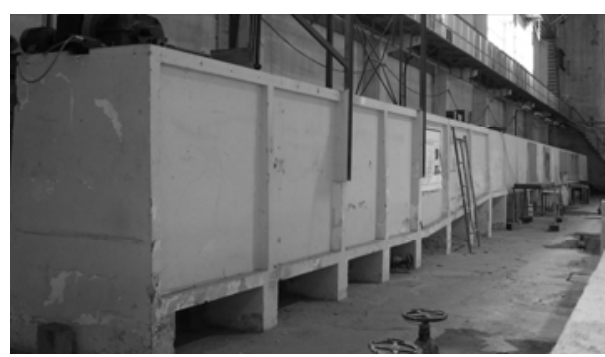

Figure 1. Wave flume.

Experiments were made in three main phases, corresponding to different wave conditions: a) Regular waves resulting from the combination of four wave periods ( $\mathrm{T}=1.1,1.5,2.0$, and $2.5 \mathrm{~s})$ and six wave heights $(\mathrm{H}=0.08,0.10,0.12,0.14,0.16$, and $0.18 \mathrm{~m})$; b) Bichromatic waves resulting from a combination of two of the previous regular waves considering a certain wave height, i.e. $\mathrm{T}=1.1$ and $1.5 \mathrm{~s}$ and $\mathrm{H}=0.06$ and $0.08 \mathrm{~m}$; c) and irregular waves (JONSWAP spectrum) with $\mathrm{T}_{\mathrm{s}}=1.5 \mathrm{~s}$ and three different wave heights $\left(\mathrm{H}_{\mathrm{s}}=0.12,0.14\right.$, and $\left.0.16 \mathrm{~m}\right), \mathrm{T}_{\mathrm{s}}=2.0 \mathrm{~s}$ and $\mathrm{H}_{\mathrm{s}}=0.12 \mathrm{~m}$, and $\mathrm{T}_{\mathrm{s}}=2.5 \mathrm{~s}$ and $\mathrm{H}_{\mathrm{s}}=0.12 \mathrm{~m}$.
For selected wave conditions two different water depths in the lee part of the bar (Fig. 2) were considered, $\mathrm{d}=0.1$ and $0.3 \mathrm{~m}$, in order to have breaking and non-breaking conditions.

This paper only presents results for one regular wave $(\mathrm{T}=1.5 \mathrm{~s}, \mathrm{H}=0.1 \mathrm{~m})$ for a $0.3 \mathrm{~m}$ water depth, corresponding to a non-breaking wave condition. This wave condition is one of six combinations, presented in Table 1 and marked with an " $x$ ", that don't produce wave breaking in the flume for this water level.

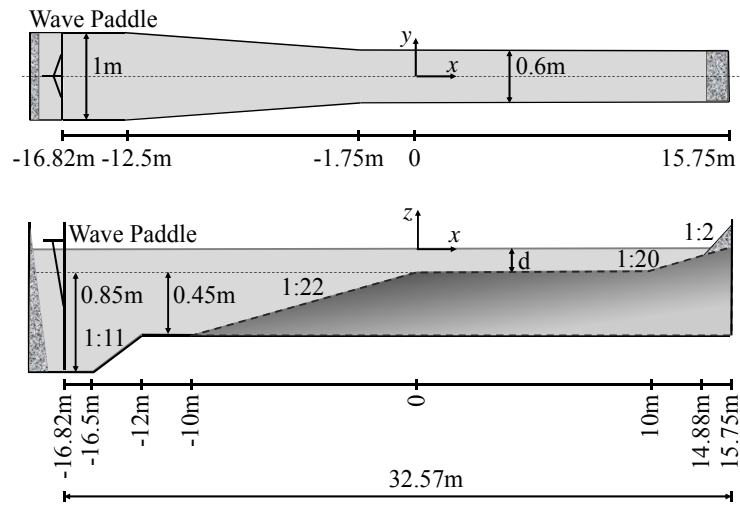

Figure 2. Wave flume's plan and longitudinal-section views.

Table 1. Non-breaking incident regular wave conditions.

\begin{tabular}{|c|c|c|c|c|}
\hline & \multicolumn{4}{|c|}{$\mathrm{T}(\mathrm{s})$} \\
\hline $\mathrm{H}(\mathrm{m})$ & 1.1 & 1.5 & 2.0 & 2.5 \\
\hline 0.08 & $\times$ & $\times$ & $\times$ & $\times$ \\
\hline 0.10 & $\times$ & $\times$ & - & - \\
\hline
\end{tabular}

The total set of experiments was divided in three phases:

I. Free surface elevation measurements along the flume with an 8 gauge mobile structure;

II. Particle velocity measurements along the flume at the middle of the water column, using an Acoustic Doppler Velocimeter (ADV) probe;

III. Longitudinal velocity component vertical profiles at selected sections along the flume using the same ADV probe.

In phase I, the free surface elevations were measured using an eight gauge mobile structure, Fig. 3. This structure was placed at different locations along the flume, and measurements were taken from the beginning of the first ramp, $x=-10 \mathrm{~m}$, till $\mathrm{x}=10 \mathrm{~m}$. A reference wave gauge was installed at the toe of the front face of the $1 / 22$ slope $(x=-10.8 \mathrm{~m})$ in order to verify the input wave height. Each gauge in the mobile structure was separated by a fixed distance $(0.20 \mathrm{~m})$, and measurements were taken along the covered area separated by $0.1 \mathrm{~m}$.

For phases II and III, the particle velocity was measured by the ADV probe, enabling the three 
orthogonal components of the suspended particle velocities, Fig. 3. Together with the ADV probe, a resistive gauge was placed for simultaneous measurements of the free surface elevation, Fig. 3. In Phase II, the ADV probe was located in the middle of the water column. Measurements were obtained between $\mathrm{x}=-10 \mathrm{~m}$ and $\mathrm{x}=8 \mathrm{~m}$, with a $1 \mathrm{~m}$ interval.

For phase III, the velocity vertical profiles were measured (separated by $5 \mathrm{~cm}$ in the vertical axis, $\mathrm{z}$ ) for selected locations $(\mathrm{x}=-10 ;-5 ;-2 ;-1 ; 0 ; 1 ; 2$; and $5 \mathrm{~m})$.

The sampling frequency of all the measurements was of $25 \mathrm{~Hz}$ and each experimental test (incident wave) has a total duration of $490 \mathrm{~s}$, from which the useful duration is 240 s.
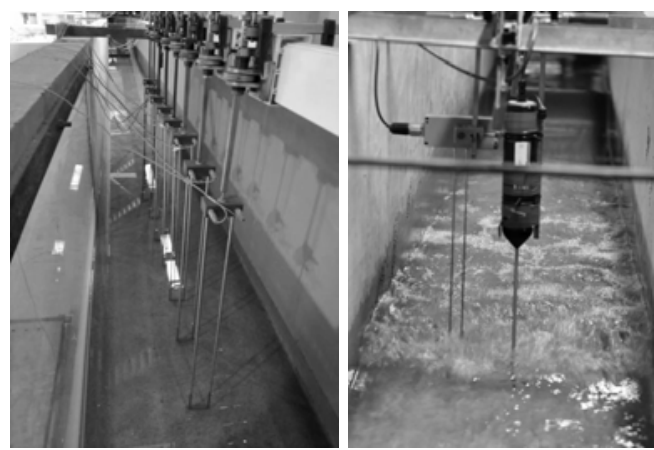

Figure 3. Eight wave gauge mobile structure (left) and the ADV probe with the wave gauge (right).

\section{RESULTS AND DISCUSSION}

For each one of the incident wave conditions, different types of data analysis were considered:

- Time and spectral analysis of the free surface elevations along the flume;

- Time analysis of the particle velocity measurements along the flume at the middle of the water column. Moreover, these results allowed the calculation of the particle velocities main characteristics and the two-dimensional distributions of velocity components in the xy, xz and yz planes;

- Velocity vertical profiles were taken in several sections along the flume.

In the next subsections, these methodologies and results are presented for the incident wave with $\mathrm{T}=1.5 \mathrm{~s}$ and $\mathrm{H}=0.1 \mathrm{~m}$.

\section{Free surface elevation}

For the free surface elevation time series, considering the incident wave conditions, were obtained along the wave flume:

- The values of significant wave height, $\mathrm{H}_{\mathrm{s}}$, and average wave period, $\mathrm{T}_{\mathrm{av}}$, based on the upcrossing method;

- Amplitude spectra at different locations along the flume. This analysis allowed the characterization of the nonlinear phenomena and the harmonic generation due to shoaling.

Figure 4 depict the wave gauge data records, at several sections along the flume $(x=-10,-5,-2,1$ and $5 \mathrm{~m}$ ) for an incident regular wave with $\mathrm{T}=1.5 \mathrm{~s}$ and $\mathrm{H}=0.1 \mathrm{~m}$, during 20 wave periods.

From this figure one can observe a clear wave transformation as it propagates to areas of lower depths. The deformed of the free surface presents increasingly non-linear characteristics (sharp crests and elongated troughs).

Figure 5 presents the amplitude spectra corresponding to wave gauge data records presented in Fig. 4. These amplitude spectra were calculated using a discrete time Fourier transform (DFT). The reference value for the amplitude, $a_{\text {ref }}$, is half of the significant wave height at the reference wave gauge $(\mathrm{x}=-10.8 \mathrm{~m}), \mathrm{H}_{\mathrm{s} \text { ref }}=0.119 \mathrm{~m}$.

The results from this analysis show that, as the wave propagates to shallower zones, the harmonics amplitude, virtually inexistent at the beginning of the slope, become more important. The increase in the amplitude of the main frequency, due to the shoaling effect, as the wave propagates in the main slope is also visible.

Figure 6 shows the significant wave height, $\mathrm{H}_{\mathrm{s}}$, and the average wave period, $\mathrm{T}_{\mathrm{av}}$, evolution along the flume. This figure shows an increase of $\mathrm{H}_{\mathrm{s}}$ throughout the flume up to $x=0$ due to the shoaling effect. For $\mathrm{x}>0$ the significant wave height is essentially the same. Some oscillations on the wave height values are also observed which may be due to wave reflection at the end of the flume. According to Conde et al. (2012), the reflection coefficient for this condition is 0.156 .

The experimental tests also show that, although there is a generation of higher order harmonics, the average wave period remains approximately constant throughout the flume.

\section{Velocity}

For each of the incident wave conditions, from the particle velocities time series were obtained:

- The minimum, average, and maximum longitudinal velocity values $\left(\mathrm{V}_{\mathrm{x} \text { min }}, \mathrm{V}_{\mathrm{x} \text { av }}, \mathrm{V}_{\mathrm{x} \text { max }}\right)$ along the flume. The average velocity values at each time series is the average of all measured values. The averages of the maximum and minimum velocities were calculated by the identification of each individual wave;

- The two-dimensional distributions of the velocity components in the three orthogonal planes at different locations along the flume;

- The minimum, average, and maximum longitudinal velocity, $\mathrm{V}_{\mathrm{x}}$, profiles, for selected positions along the flume.

Figure 7 presents the velocity components time series, at the position $\mathrm{x}=-10 \mathrm{~m}, \mathrm{y}=0$, and $\mathrm{z}=-0.15 \mathrm{~m}$. 

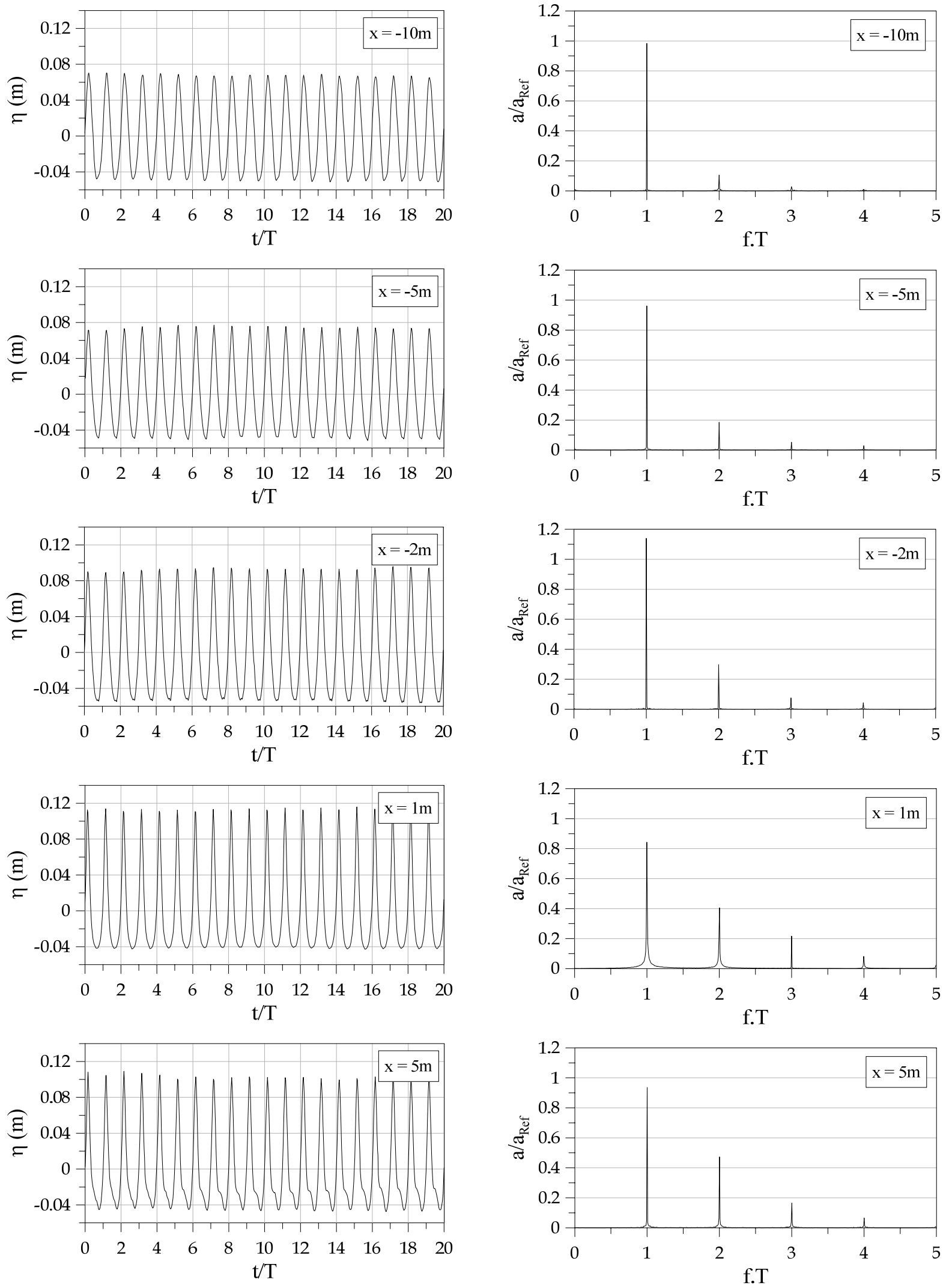

Figure 4. Free surface elevation time series, $\eta$, for an incident wave with $\mathrm{T}=1.5 \mathrm{~s}$ and $\mathrm{H}=0.1 \mathrm{~m}$, at different sections, $\mathrm{x}$, along the flume.

Figure 5. Amplitude spectra, a, for an incident wave with $\mathrm{T}=1.5 \mathrm{~s}$ and $\mathrm{H}=0.1 \mathrm{~m}$, at different sections, $\mathrm{x}$, along the flume. 

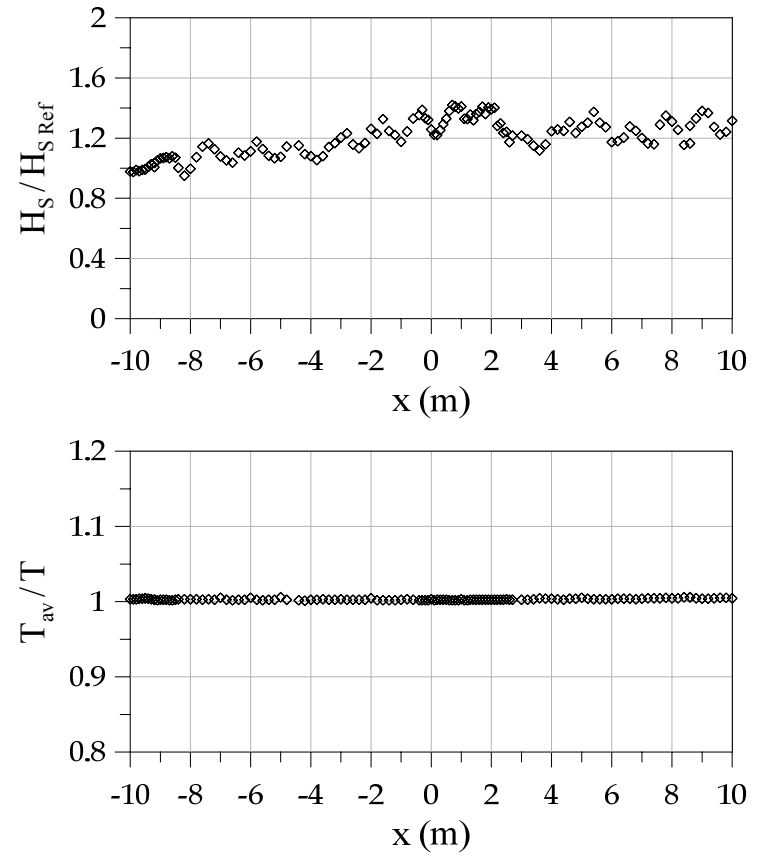

Figure 6. Significant wave height, $\mathrm{H}_{\mathrm{s}}$, and wave average period, $\mathrm{T}_{\mathrm{av}}$, along the flume.

Figure 8 presents the minimum, average, and maximum longitudinal velocity values $\left(\mathrm{V}_{\mathrm{x} \text { min }}, \mathrm{V}_{\mathrm{x} \text { av }}\right.$, $\mathrm{V}_{\mathrm{x} \max }$ ) along the flume. One observes that there is a slightly increase of absolute value of $\mathrm{V}_{\mathrm{x} \max }$ and $\mathrm{V}_{\mathrm{x} \text { min }}$ due to the bottom variation up to $x=0$. For $x>0$ the values are almost constant. Note that along the flume the symmetry between $\mathrm{V}_{\mathrm{x} \max }$ and $\mathrm{V}_{\mathrm{x} \text { min }}$ is not maintained (propagation of nonlinear waves), being the $V_{x \max }$ higher than the absolute value of $V_{x \min }$.

The analysis of the two-dimensional distributions of the velocity components in the $\mathrm{xy}, \mathrm{xz}$ and yz planes is performed in Fig. 9, 10 and 11.

Figure 9 presents the recorded data clouds distribution at $\mathrm{x}=-10 \mathrm{~m}, \mathrm{y}=0$ and $\mathrm{z}=-0.15 \mathrm{~m}$. It is visible a distorted elliptical shape in the xz plane with a dispersion of points around its' average line. A dispersion of points around zero is also visible in the $\mathrm{xy}$ and yz planes, this is a consequence of the $\mathrm{V}_{\mathrm{y}}$ fluctuation around zero.

Figure 10 presents the recorded data clouds evolution, in the $\mathrm{xz}$ plane, along the longitudinal axis at different $x$ locations with $y=0$ and $z=-0.15 m$. As $x$ increases the elliptical shape becomes larger and the aspect ratio changes (e.g. flatten ellipse at $x=-2 m$ ), this is a direct consequence of the shoaling effect.

One way to quantify the aspect ratio of the elliptical form and the dispersion of the cloud of points is through the values of $E_{x}, E_{y}$ and $E_{z}$. These variables are the difference between the averages of the positive and negative velocities for each orthogonal component. The $\mathrm{E}_{\mathrm{z}} / \mathrm{E}_{\mathrm{x}}, \mathrm{E}_{\mathrm{y}} / \mathrm{E}_{\mathrm{x}}$ and $\mathrm{E}_{\mathrm{y}} / \mathrm{E}_{\mathrm{z}}$ ratios, presented in Fig. 11 for an incident wave condition of $\mathrm{T}=1.5 \mathrm{~s}$ and $\mathrm{H}=0.1 \mathrm{~m}$, permit the velocity components distribution analyses along the flume.
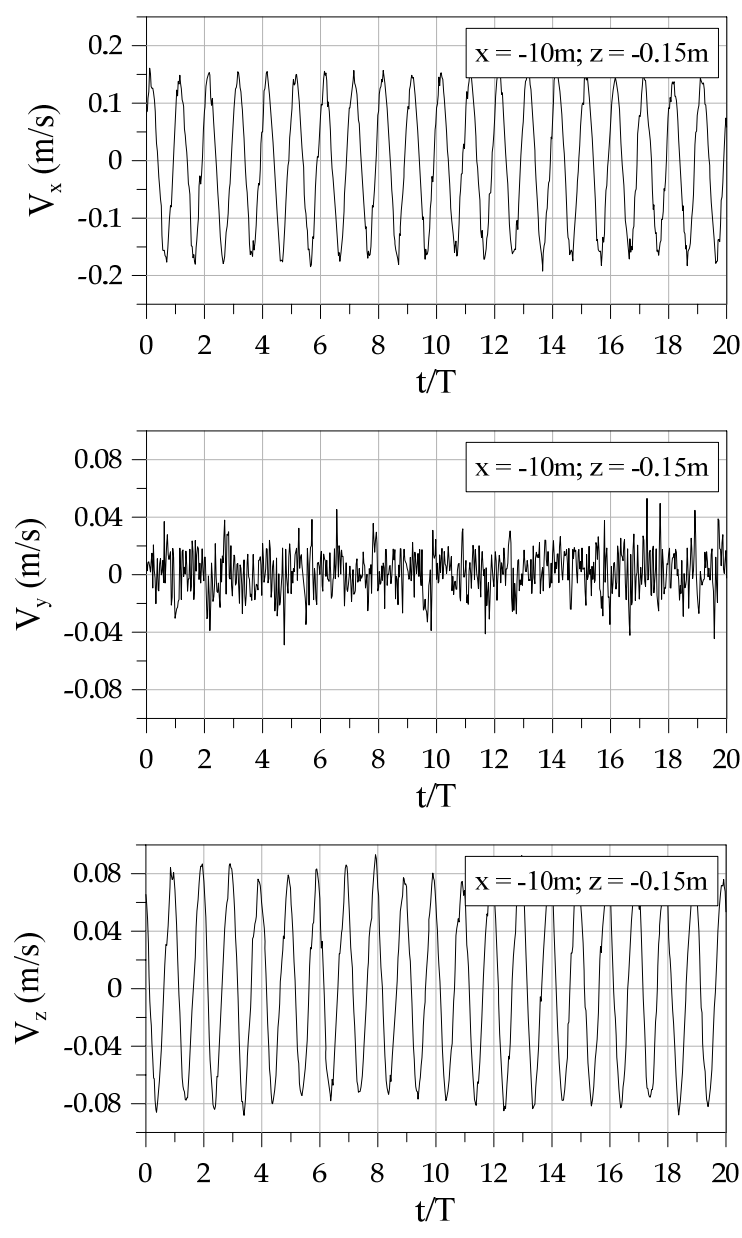

Figure 7. Velocity components time series, at the position $\mathrm{x}=-10 \mathrm{~m}, \mathrm{y}=0$, and $\mathrm{z}=-0.15 \mathrm{~m}$.

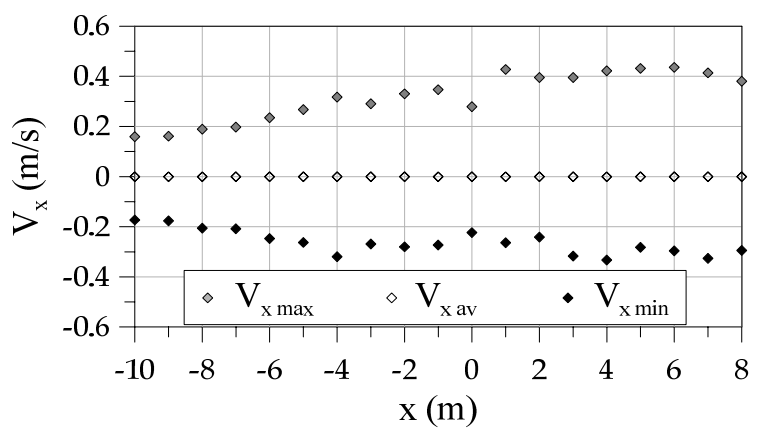

Figure 8. Minimum, average, and maximum longitudinal velocity values $\left(\mathrm{V}_{\mathrm{x} \text { min }}, \mathrm{V}_{\mathrm{x} \text { av }}, \mathrm{V}_{\mathrm{x} \text { max }}\right)$ along the flume.

Table 2 presents the criteria used on the analysis of the cloud of points' shape characterization along the flume.

Figure 11 shows that from the beginning of the $1 / 22$ slope up to almost half of it $(-10 \mathrm{~m}<\mathrm{x}<-6 \mathrm{~m})$ the ratios present little variation. The value $\mathrm{E}_{\mathrm{z}} / \mathrm{E}_{\mathrm{x}} \approx 0.5$ represents a mean longitudinal elongation. The values $\mathrm{E}_{\mathrm{y}} / \mathrm{E}_{\mathrm{x}} \approx 0.1$ and $\mathrm{E}_{\mathrm{y}} / \mathrm{E}_{\mathrm{z}} \approx 0.2$ show an approximation to the ideal values $\mathrm{E}_{\mathrm{y}} / \mathrm{E}_{\mathrm{x}}=\mathrm{E}_{\mathrm{y}} / \mathrm{E}_{\mathrm{z}}=0$, meaning almost zero transversal component $\left(\mathrm{V}_{\mathrm{y}}=0\right)$. 


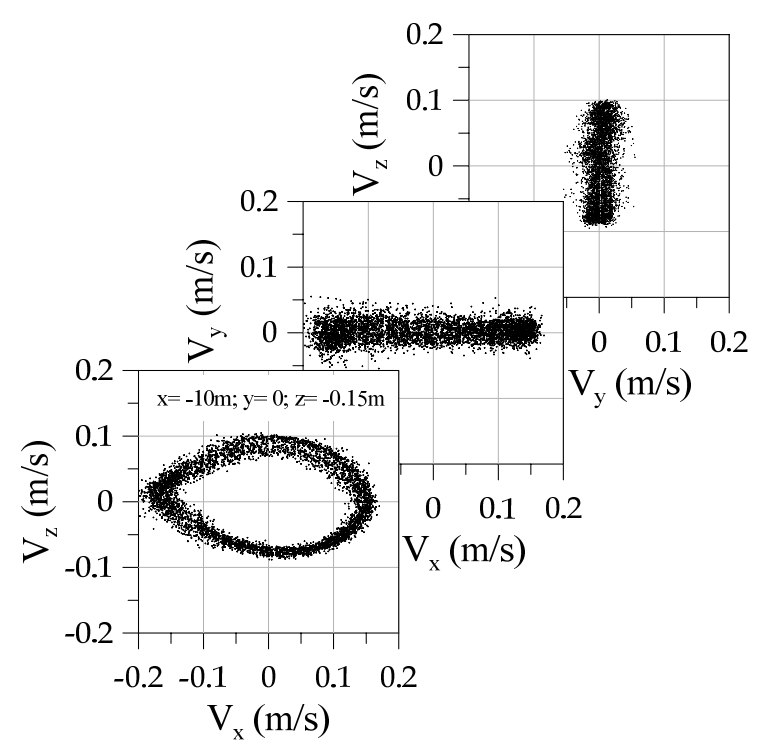

Figure 9. Two-dimensional distribution of the velocity components: recorded data cloud at $\mathrm{x}=-10 \mathrm{~m}$, $\mathrm{y}=0$ and $\mathrm{z}=-0.15 \mathrm{~m}$.

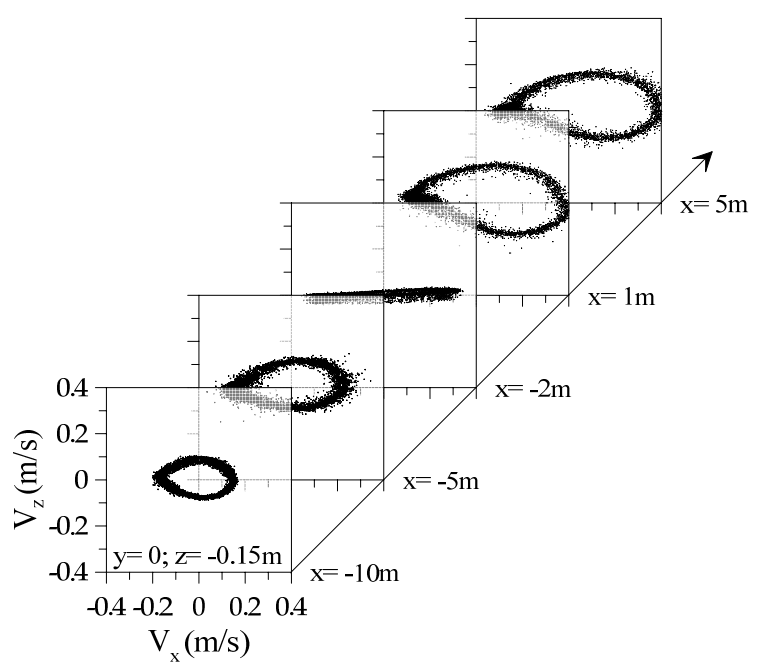

Figure 10. Two-dimensional distribution of the velocity components: recorded data clouds evolution along the longitudinal axis at different locations with $\mathrm{y}=0$ and $\mathrm{z}=-0.15 \mathrm{~m}$.

Table 2. Results interpretation for the $\mathrm{E}_{\mathrm{z}} / \mathrm{E}_{\mathrm{x}}, \mathrm{E}_{\mathrm{y}} / \mathrm{E}_{\mathrm{x}}$ and $\mathrm{E}_{\mathrm{y}} / \mathrm{E}_{\mathrm{z}}$ ratios.

\begin{tabular}{|c|c|c|}
\hline Ratio & Result & Graphical form \\
\hline $\mathrm{E}_{\mathrm{z}} / \mathrm{E}_{\mathrm{x}}$ & $>1$ & Elongated vertically \\
& $0<\mathrm{E}_{\mathrm{z}} / \mathrm{E}_{\mathrm{x}}<1$ & Circular \\
& $=0$ & Elongated longitudinally \\
\hline $\mathrm{E}_{\mathrm{y}} / \mathrm{E}_{\mathrm{x}}$ & $>0$ & Transversal component $\neq 0$ \\
\hline & $=0$ & Line (ideal condition) \\
$\mathrm{E}_{\mathrm{y}} / \mathrm{E}_{\mathrm{z}}$ & $>0$ & Transversal component $\neq 0$ \\
\hline
\end{tabular}
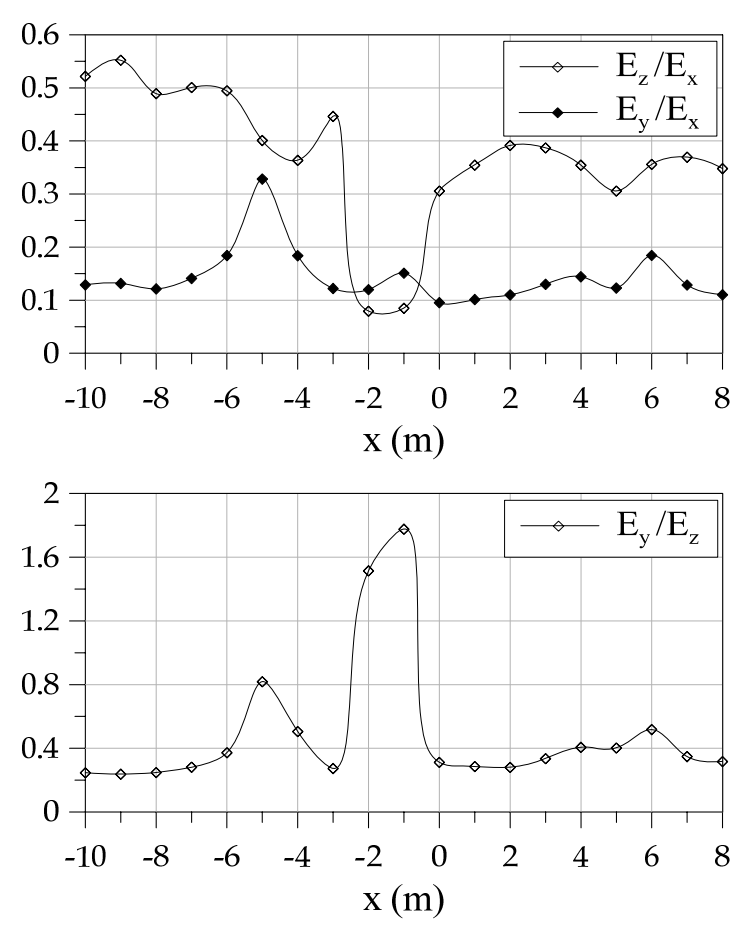

Figure 11. $E_{z} / E_{x}, E_{y} / E_{x}$ and $E_{y} / E_{z}$ ratios along the flume.

In the central zone of the $1 / 22$ slope $(-6 m<x<$ $-3 \mathrm{~m})$ an oscillation on the three aspect ratios is observed, followed by a considerable diminution of the $E_{z}$ parameter, corresponding to an increase of the longitudinal aspect ratio at almost the end of the slope $(-3 m<x<-1 m)$, from there up to the top of the slope $(-1 \mathrm{~m}<\mathrm{x}<0)$ the value $\mathrm{E}_{\mathrm{z}} / \mathrm{E}_{\mathrm{x}}$ increase and $\mathrm{E}_{\mathrm{y}} / \mathrm{E}_{\mathrm{z}}$ decreases. From the top of the slope up to $\mathrm{x}=8 \mathrm{~m}$, the values present little variation, the ratio $E_{z} / E_{x} \approx 0.35$ corresponds to an increase of the longitudinal elongation, the values $\mathrm{E}_{\mathrm{y}} / \mathrm{E}_{\mathrm{x}} \approx 0.15$ and $\mathrm{E}_{\mathrm{y}} / \mathrm{E}_{\mathrm{z}} \approx 0.35$ correspond to the difference from the ideal condition $\left(\mathrm{V}_{\mathrm{y}}=0\right)$.

Figure 12 presents the vertical profiles of the minimum, average, and maximum longitudinal velocity for selected positions along the flume. As one can see there is an almost symmetry between the maximum and minimum for the deeper regions of the flume. As the wave propagates along the flume, the symmetry is lost but the average value is near zero. This is due to shoaling. There is some variability of the values, which may be due to the inaccuracies of the velocity measurements.

\section{CONCLUSIONS}

In this paper, recent physical modelling tests on a wave flume at the National Laboratory for Civil Engineering (LNEC), Lisbon, Portugal, were presented. This is contribution for the study of the wave propagation hydrodynamics in varying slopping beaches. The main objective was to study in detail all the process related with the wave propagation in complex bathymetries. 

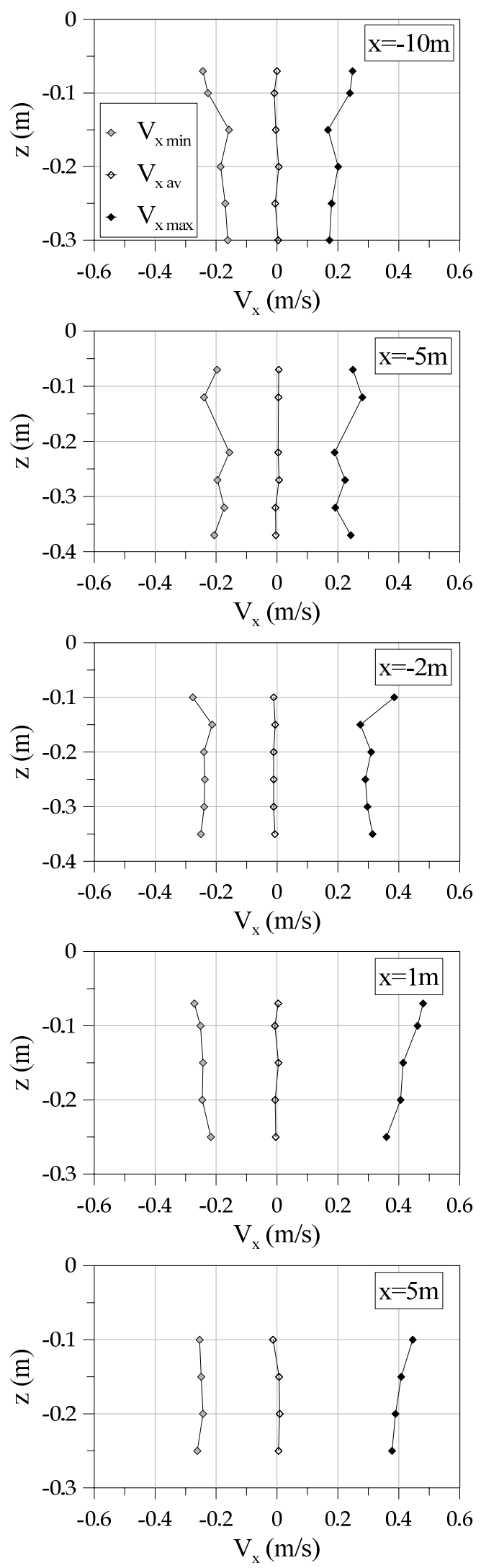

Figure 12. Vertical profiles of the minimum, average, and maximum longitudinal velocity for selected positions along the flume.
The physical modelling was performed on a wave channel, with a bottom characterized by several ramps with different slopes, forming a characteristic beach profile. Test comprises several wave conditions (regular and irregular waves), in breaking and non-breaking wave conditions. The measurements were made with resistive gauges (free surface elevation) and an Acoustic Doppler Velocimeter (ADV). A time and spectral analysis of the free surface elevation was made. Twodimensional distribution of the velocity components in the $x y, x z$ and yz planes and vertical profiles for the longitudinal velocity at specific locations along the flume were also made.

The time analysis of the free surface showed that the significant wave heights increase until $\mathrm{x}=0$, due to shoaling. From there up to the end of flume, the average wave height value is almost constant, although there are some oscillations. Those oscillations may be due to reflexions at the end of the flume. The average wave period is constant along the entire flume. The spectral analysis showed that there is a generation of higher order harmonics along the flume.

Regarding the velocity longitudinal component $\left(\mathrm{V}_{\mathrm{x}}\right)$ along the flume, there is a slightly increase of the absolute maximum and minimum values, $V_{x \max }$ and $\mathrm{V}_{\mathrm{x} \text { min }}$, up to $\mathrm{x}=0$ due to the bottom slope. For $\mathrm{x}>0$ values are almost constant. The symmetry between $\mathrm{V}_{\mathrm{x} \max }$ and $\mathrm{V}_{\mathrm{x} \text { min }}$ is not maintained, which confirms the nonlinear wave propagation characteristics.

The analysis of the velocity components twodimensional distributions in the $\mathrm{xy}, \mathrm{xz}$ and $\mathrm{yz}$ planes is a way to analyse the wave shape along the flume. As the water depth diminishes, there is an increase of oscillations in the wave shape (along the $\mathrm{xz}$ plane) and in the transversal component. When the water depth becomes constant, there is a decrease of those oscillations, although the transversal component values still remain higher than the ideal condition.

Finally, regarding the velocity vertical profiles, the existent symmetry between the maximum and minimum in the deeper regions of the flume is lost, as the wave propagates along the flume. The average value is near zero along the flume. There is some variability of the values, which may be due to the inaccuracies of the velocity measurements.

\section{ACKNOWLEDGEMENTS}

This work has been developed at LNEC within the scope of the J. M. P. Conde sabbatical leave from Universidade Nova de Lisboa (Portugal). The support by the FCT projects HIDRALERTA (PTDC/AAC$\mathrm{AMB} / 120702 / 2010$ and EROS (PTDC/CTEGIX/111230/2009) is acknowledged. The assistance of Mariana Fernandes and Ana Mesquita in the experiments is also acknowledged. 


\section{REFERENCES}

Conde, J. M. P., Capitão, R., Neves, M. G., and Fortes, C. J. E. M., 2012, Comparison of Various Techniques of Passive Absorption of Waves with Assessment of Incident and Reflected Agitation in a Wave Flume (in Portuguese), in: Proc. 2nd Hydrographic Engineering Workshop, Hydrographic Institute, Lisbon, Portugal.

Endres, L., Neves, D. R. C. B., Didier, E., Fortes, C. J. E. M., and Okamoto T., 2011, Performance Evaluation of Numerical Models to Simulate Waves Along a Wave Channel (in Portuguese), in: Proc. Congress of Numerical Methods in Engineering (CMNE2011), Coimbra, Portugal.

Okamoto, T., Fortes, C. J. E. M., and Basco, D. R., 2010, Bore Propagation Speed at the Termination of Wave Breaking, in: Proc. of 32nd International Conference on Coastal Engineering, Shanghai, China.

Neves, D. R. C. B., Endres, L., Fortes, C. J. E. M., and Okamoto T., 2011, Physical Modelling of Wave Propagation and Wave Breaking in a Wave Channel, in: Proc. of the 5th SCACR International Short Conference on Applied Coastal Research, Aachen, Germany.

Neves, D. R. C. B., Endres, L. A. M., Fortes, C. J. E. M., and Okamoto, T, 2012, Directional Spreading Model in a Wave Channel: Wave Propagation and Wave Breaking, Ocean Engineering, Vol. 55, pp. 148-160.

Received: September 30, 2012

Revised: October 30, 2012

Accepted: November 30, 2012 